PREHOSPITAL CARE

\title{
A systematic review of the safety of analgesia with $50 \%$ nitrous oxide: can lay responders use analgesic gases in the prehospital setting?
}

\author{
S C Faddy, S R Garlick
}

Emerg Med J 2005;22:901-906. doi: 10.1136/emj.2004.020891

A safe and effective form of pain relief would be an advantage in the prehospital treatment of patients experiencing extreme pain. Although used by many emergency medical services, 50\% nitrous oxide (an inhaled analgesic known to have good pain relief properties) is not widely used by volunteer and semiprofessional organisations. This review aimed to determine whether $50 \%$ nitrous oxide is safe for use by first responders who are not trained as emergency medical technicians. A thorough search of the literature identified 12 randomised controlled trials investigating the use of $50 \%$ nitrous oxide (as compared with placebo or conventional analgesic regimens) in a range of conditions. The outcomes analysed for this review were: adverse events, recovery time, and need for additional medication. None of the studies compared the treatments in the prehospital setting; children were well represented. Adverse effects were rare and significant adverse outcomes such as hypotension and oxygen desaturation could not be attributed to nitrous oxide. Compared with patients receiving conventional analgesia, those receiving 50\% nitrous oxide did not require additional medication any more frequently and had a faster recovery from sedative effects. The low incidence of significant adverse events from $50 \%$ nitrous oxide suggests that this agent could be used safely by lay responders.

See end of article for authors' affiliations

Correspondence to: S Faddy, Cardiac Catheterisation Unit, St Vincent's Hospital, Sydney; Victoria Street Darlinghurst, NSW, 2010, Australia; sfaddy@health. usyd.edu.au

Accepted for publication 14 December 2004
$\mathrm{P}$ ain is a common aspect of many medical emergencies and is of major concern to caregivers treating patients in the prehospital setting. The availability of pain relief is limited in out-of-hospital emergencies, with the use of intravenous analgesics (such as opioids) largely confined to paramedics and medical retrieval teams. Nevertheless, significant pain can render a patient uncooperative and can affect the appropriateness, timing, and effectiveness of treatments applied by primary care providers.

Many patients are treated by members of volunteer or semiprofessional aid organisations prior to the arrival of the emergency medical services (EMS). Groups such as lifeguards, marine rescue, ski patrols, and mountain and mine rescue teams provide the initial care to a variety of patients. These organisations do not provide the standard of training that allows their members to administer intravenous analgesics. For members of these groups to effectively treat patients in extreme pain, they need to have a safe and effective alternative form of pain relief at their disposal. Fifty per cent nitrous oxide in oxygen (commercially available as a mixture in a single cylinder) is a patient controlled, inhaled analgesic, which has been used by many emergency medical services for many years. However, it is used by only a selected few organisations employing non-medically trained personnel. Use of formal pain management such as nitrous oxide varies widely between different organisations throughout the world.

Nitrous oxide has low solubility in blood and is transported in solution without binding to protein. It diffuses rapidly across the alveolararterial membrane and is excreted unchanged, mainly through the lungs. ${ }^{1}$ As a result, nitrous oxide rapidly takes effect ${ }^{2}$ and is quickly reversible on discontinuation of therapy. ${ }^{2-3}$ Hence, nitrous oxide does not mask signs and symptoms that may later be necessary for definitive diagnosis of the injury or illness. The $50 \%$ oxygen content of $50 \%$ nitrous oxide:oxygen mixtures is beneficial in ensuring adequate oxygenation and has been shown to result in higher oxygen tension $\left(\mathrm{PO}_{2}\right)$ compared with oxygen given through a standard oxygen therapy mask at a flow rate of $5 \mathrm{l} / \mathrm{min}$. $^{4}$ Clinically unimportant decreases in arterial oxygen saturation $\left(\mathrm{SaO}_{2}\right)$ have been noted in patients breathing 50\% nitrous oxide in oxygen compared with 50\% or $79 \%$ nitrogen in oxygen under conditions of normoventilation. ${ }^{5}$

Diffusion hypoxia has been identified as a potential complication of treatment with 50\% nitrous oxide, at least theoretically. ${ }^{5-8}$ For this reason, some authors have advocated a period of oxygen therapy immediately following the cessation of nitrous oxide inhalation.' Although theoretically a risk, several studies have failed to demonstrate diffusion hypoxia after 50\% nitrous oxide inhalation. ${ }^{13} 710$ The safety profile of any analgesic is irrelevant unless it is efficacious in the relief of pain. To this end, we have previously presented data showing remarkable consistency in efficacy of pain relief in studies comparing $50 \%$ nitrous oxide with placebo or conventional medication regimens. ${ }^{11}$ We used previously validated pain scoring systems, such as, visual analogue scales (VAS), 
FACES rating scale, the Children's Hospital of Eastern Ontario Pain Scale (CHEOPS), and verbal pain scores to assess the analgesic properties of $50 \%$ nitrous oxide. Studies in a variety of patients using a range of scoring systems consistently showed superiority of $50 \%$ nitrous oxide over placebo, and equivalence when compared with conventional medication regimens.

The present systematic review assessed the available literature to determine the safety profile of $50 \%$ nitrous oxide. We carefully examined the frequency and severity of side effects to determine whether this agent is safe enough to be used by caregivers who are not trained as emergency medical technicians (EMTs).

\section{MATERIALS AND METHODS Literature search}

One reviewer performed all of the literature searches. The Cochrane Database of Systematic Reviews (Issue 2, 2001) was searched for reviews of trials comparing nitrous oxide with placebo or other analgesic agents in the prehospital setting. No such review existed. The database was further searched for a review of similar trials in any setting. There were no reviews specifically involving the use of nitrous oxide in any area of patient care.

The reviewer searched the Medline (1966-Oct 2001) and EMBASE (1985-Oct 2001) databases, using an optimally sensitive search strategy, for relevant studies comparing 50\% nitrous oxide with placebo or other analgesic agents in the prehospital setting. Again, no studies in the prehospital setting were found. Consequently, a broader search was performed to find randomised controlled trials from a wide range of clinical settings. Reference lists cited in original articles were examined for relevant studies not identified by the literature search.

\section{Inclusion criteria}

Previous studies have demonstrated increasing analgesic and psychomotor effects with increasing concentrations of nitrous oxide. ${ }^{12-14}$ In Australia, the USA, and Europe, 50\% nitrous oxide in oxygen is the only premixed concentration commercially available. Therefore, we considered only those randomised controlled studies comparing 50\% nitrous oxide with either placebo or another form of analgesia for inclusion in the review.

\section{Outcomes analysed}

The main outcomes were adverse effects resulting from treatment with $50 \%$ nitrous oxide, compared with either placebo or conventional analgesia. Secondary outcomes included recovery time and the need for additional medication.

\section{Quality assessment and data extraction}

Two reviewers independently assessed the quality of each trial. Any disagreement in interpretation of the studies between the reviewers was resolved by discussion. Quality assessment of each study was based on the methodological description of each study, in particular, randomisation, allocation concealment, blinding, and equality of baseline variables.

\section{Statistical analysis}

We used MetaView (Review Manager version 4.1 for Windows, Oxford, England; the Cochrane Collaboration, 2000) to calculate pooled risk differences and assess statistical heterogeneity. Statistical heterogeneity was a strong possibility in this review because of the wide range of patient populations, sources of pain, and control medication regimens employed in the primary studies. We used a random effects model for the pooled analysis because of the clinical heterogeneity in the primary studies.

For each adverse effect, we have given the risk difference (RD) and 95\% confidence interval (CI) from studies comparing nitrous oxide and placebo to allow estimation of the rate of events which may be attributed to the nitrous oxide treatment over and above those that would have occurred because of the injury or illness. Test statistics and $p$ values are those reported by each study or, where sufficient data were given, have been independently estimated using Prism version 2.01 (GraphPad Software Inc, San Diego, CA). A p value less than or equal to 0.05 was considered statistically significant.

\section{RESULTS}

\section{Literature search}

From the electronic search of the Medline and EMBASE databases we identified 1585 citations that matched the search criteria. These were screened for potentially relevant studies. A total of 158 abstracts were retrieved for more detailed evaluation, of which 33 described studies that were potentially relevant to this systematic review. These studies underwent critical appraisal. Twelve studies satisfied all subject and methodology criteria and were subsequently included in the review.

\section{Characteristics of the studies}

The characteristics of the studies included in the analysis are shown in table 1; 50\% nitrous oxide was compared with control (placebo or conventional analgesia) in a wide variety of patient populations. Importantly, child, adolescent, and adult patients were all well represented. Pain was experienced from a variety of sources, many of which mimic injuries and conditions seen in the prehospital setting. The methodological quality of included studies is described in table 2. As expected from studies with short follow up periods, collection of outcome data was complete in almost all studies.

\section{Adverse effects}

Analysis of the pooled risk differences showed that none of the side effects investigated were significantly associated with nitrous oxide analgesia (fig 1).

\section{Nausea}

Nausea was assessed in 234 patients from three studies comparing 50\% nitrous oxide and placebo. ${ }^{14-16}$ This analysis lacks power, as there were only two reports of nausea in the three studies. The incidence of nausea was $1.7 \%$ in all patients treated with nitrous oxide. There were no reports of nausea in patients treated with placebo (RD 1.7\%, CI $-2 \%$ to $5 \%, \mathrm{p}=0.4)$. Hence, there is no significant association between nitrous oxide inhalation and nausea. Evans et al reported no cases of nausea among a small sample of children undergoing fracture reduction with either $50 \%$ nitrous oxide or intramuscular sedation. Notini-Gudmarsson et $a l^{10}$ measured the degree of nausea in adult patients undergoing colonoscopy using a 0-100 mm VAS. The mean (SD) score was significantly lower in the patients treated with nitrous oxide than in those treated with pethidine $(4$ (8) $v 15$ (21), respectively; $\mathrm{p}<0.05$ ).

\section{Vomiting}

Four studies, comprising a total of 187 patients, examined the incidence of vomiting in patients treated with 50\% nitrous oxide compared with placebo. ${ }^{16-19}$ Once again, this analysis lacked power as there were only two events reported in patients treated with nitrous oxide and no reports in patients treated with placebo (RD 2\%, $95 \%$ CI $-3 \%$ to $6 \%$, $\mathrm{p}=0.5$ ), and the vomiting could not definitely be attributed 
Table 1 Characteristics of trials of $50 \%$ nitrous oxide for pain relief

\begin{tabular}{|c|c|c|c|c|c|}
\hline Study & $\begin{array}{l}\text { No } \\
\text { analysed }\end{array}$ & Participants* & Pain source & Comparative intervention & Outcomes assessed \\
\hline Castera ef al, $2001^{15}$ & 100 & $\begin{array}{l}44.4(12.5) \text { years } t \\
60 \% \text { male }\end{array}$ & $\begin{array}{l}\text { Percutaneous } \\
\text { liver biopsy }\end{array}$ & Placebo: oxygen & AE: nausea, headache \\
\hline $\begin{array}{l}\text { Forbes and Collins, } \\
2000^{22}\end{array}$ & 102 & $48(19-80)$ years & Colonoscopy & $\begin{array}{l}\text { IV sedation: midazolam + } \\
\text { meperidine }\end{array}$ & Recovery \\
\hline Triner et al, $1999^{19}$ & 22 & $\begin{array}{l}31(8.9) \text { years } † \\
14 \% \text { male }\end{array}$ & Migraine & Placebo: $100 \%$ oxygen & AE: vomiting, additional medication \\
\hline Burton et al, $1998^{17}$ & 30 & $3.7(1.6)$ years $\dagger$ & $\begin{array}{l}\text { Laceration } \\
\text { repair }\end{array}$ & Placebo: $100 \%$ oxygen & $\mathrm{AE}$ : vomiting, dizziness, oxygen desaturation \\
\hline $\begin{array}{l}\text { Notini-Gudmarsson et al, } \\
1996^{10}\end{array}$ & 38 & $60(29-83)$ years & Colonoscopy & IM sedation: pethidine & $\begin{array}{l}\text { AE: nausea, dizziness, headache, oxygen } \\
\text { desaturation } \\
\text { Recovery: beginning of procedure to discharge } \\
\text { Additional medication }\end{array}$ \\
\hline Saunders et al, $1995^{16}$ & 91 & $\begin{array}{l}63.9(53-75) \text { years } \ddagger \\
63 \% \text { male }\end{array}$ & Colonoscopy & Placebo: oxygen & $\begin{array}{l}\text { AE: nausea, vomiting, dizziness, drowsiness, } \\
\text { headache }\end{array}$ \\
\hline Evans et al, $1995^{1}$ & 30 & $\begin{array}{l}10(4-15) \text { years } \\
63 \% \text { male }\end{array}$ & $\begin{array}{l}\text { Fracture } \\
\text { reduction }\end{array}$ & $\begin{array}{l}\text { IM sedation: meperidine + } \\
\text { promethazine }\end{array}$ & $\begin{array}{l}\text { AE: nausea, vomiting } \\
\text { Recovery: time in outpatient area }\end{array}$ \\
\hline Saunders et al, $1994^{20}$ & 89 & $\begin{array}{l}46(17-74) \text { years } \\
43 \% \text { male }\end{array}$ & Colonoscopy & $\begin{array}{l}\text { Placebo: air } \\
\text { IV sedation: midazolam }+ \\
\text { pethidine }\end{array}$ & $\begin{array}{l}\text { AE: hypotension, oxygen desaturation } \\
\text { Recovery: Patient declared fit to leave } \\
\text { department } \\
\text { Additional medication }\end{array}$ \\
\hline Lindblom et al, $1994^{21}$ & 50 & $43(30-56) \oplus$ & Colonoscopy & $\begin{array}{l}\text { IV sedation: ketobemidone + } \\
\text { midazolam }\end{array}$ & Recovery: Patient chose to leave recovery area \\
\hline Henderson et al, $1990^{14}$ & 165 & $\begin{array}{l}52 \% \text { male } \\
\text { Paediatric }\end{array}$ & $\begin{array}{l}\text { Venous } \\
\text { cannulation }\end{array}$ & Placebo: $100 \%$ oxygen & $\begin{array}{l}\text { Additional medication } \\
\text { AE: nausea, additional medication }\end{array}$ \\
\hline Harrison et al, $1987^{23}$ & 170 & Adult women & Labour & $\begin{array}{l}\text { IM sedation: pethidine + } \\
\text { promizine } \\
\text { Epidural: bupivacaine }\end{array}$ & \\
\hline Kerr et al, $1975^{18}$ & 81 & $\begin{array}{l}56(31-72) \text { years } \\
88 \% \text { male }\end{array}$ & Chest pain & Placebo: air & $\mathrm{AE}:$ vomiting, drowsiness \\
\hline
\end{tabular}

to nitrous oxide inhalation. In a small group of children treated with $50 \%$ nitrous oxide or intramuscular sedation for fracture reduction there were no reports of vomiting. ${ }^{1}$

\section{Dizziness}

Two studies investigated dizziness in patients treated with $50 \%$ nitrous oxide or placebo. ${ }^{16}{ }^{17}$ Pooled analysis of risk difference between nitrous oxide and placebo showed no association between nitrous oxide inhalation and dizziness (RD $10 \%, 95 \%$ CI $-20 \%$ to $41 \%$ ), but the analysis showed significant statistical heterogeneity $\left(\chi^{2}=6.13, \mathrm{df}=1\right.$, $\mathrm{p}=0.01$ ). Consequently this result should be treated with caution. Notini-Gudmarsson et $a l^{10}$ found that fewer patients treated with nitrous oxide reported dizziness compared with those treated with intramuscular pethidine (10\% $v 26 \%$, respectively; $\mathrm{p}=0.4$ ).

Table 2 Methodological quality of trials of $50 \%$ nitrous oxide for pain relief

\begin{tabular}{|c|c|c|c|}
\hline Study & $\begin{array}{l}\text { Loss to follow up } \\
\text { (n/N (\%)) }\end{array}$ & $\begin{array}{l}\text { Method of randomisation and } \\
\text { allocation concealment }\end{array}$ & Blinding \\
\hline Castera et al, $2001^{15}$ & $0 / 100(0)$ & $\begin{array}{l}\text { Random numbers. Allocation } \\
\text { concealment not stated }\end{array}$ & Nurse and patient \\
\hline Forbes and Collins $2000^{22}$ & $0 / 102(0)$ & $\begin{array}{l}\text { States randomised. Allocation } \\
\text { concealment not stated }\end{array}$ & None \\
\hline Triner et al, $1999^{19}$ & $0 / 22(0)$ & $\begin{array}{l}\text { Computer-generated sequence, } \\
\text { sealed envelopes }\end{array}$ & Investigators and patient \\
\hline Burton et al, $1998^{17}$ & $0 / 30(0)$ & $\begin{array}{l}\text { Computer sequence generated by } \\
\text { nurse not involved in study }\end{array}$ & Investigators and patient \\
\hline $\begin{array}{l}\text { Notini-Gudmarsson et al, } \\
1996^{10}\end{array}$ & $2 / 40(5)$ & $\begin{array}{l}\text { Randomly assigned. Allocation } \\
\text { concealment not stated }\end{array}$ & Not stated \\
\hline Saunders et al, $1995^{16}$ & $0 / 131(0)$ & $\begin{array}{l}\text { Randomly allocated. Allocation } \\
\text { concealment not stated }\end{array}$ & Investigators and patient \\
\hline Evans et al, $1995^{1}$ & $0 / 30(0)$ & $\begin{array}{l}\text { Sealed unmarked envelopes from } \\
\text { box }\end{array}$ & Not stated \\
\hline Saunders et al, $1994^{20}$ & $0 / 89(0)$ & Stratified block randomisation & Investigators and patient \\
\hline Lindblom et al, $1994^{21}$ & $0 / 50(0)$ & $\begin{array}{l}\text { Block randomisation, blocks of } \\
\text { 10. Closed envelopes }\end{array}$ & Investigators and patient \\
\hline Henderson et al, $1990^{14}$ & Not stated & Not stated & Outcome assessor \\
\hline Harrison et al, $1987^{23}$ & $0 / 70(0)$ & Patient's choice of analgesia & Unclear \\
\hline Kerr et al, $1975^{18}$ & $35 / 116(30)$ & $\begin{array}{l}\text { Block randomisation. Sequentially } \\
\text { numbered cylinders }\end{array}$ & Investigator and patient \\
\hline
\end{tabular}




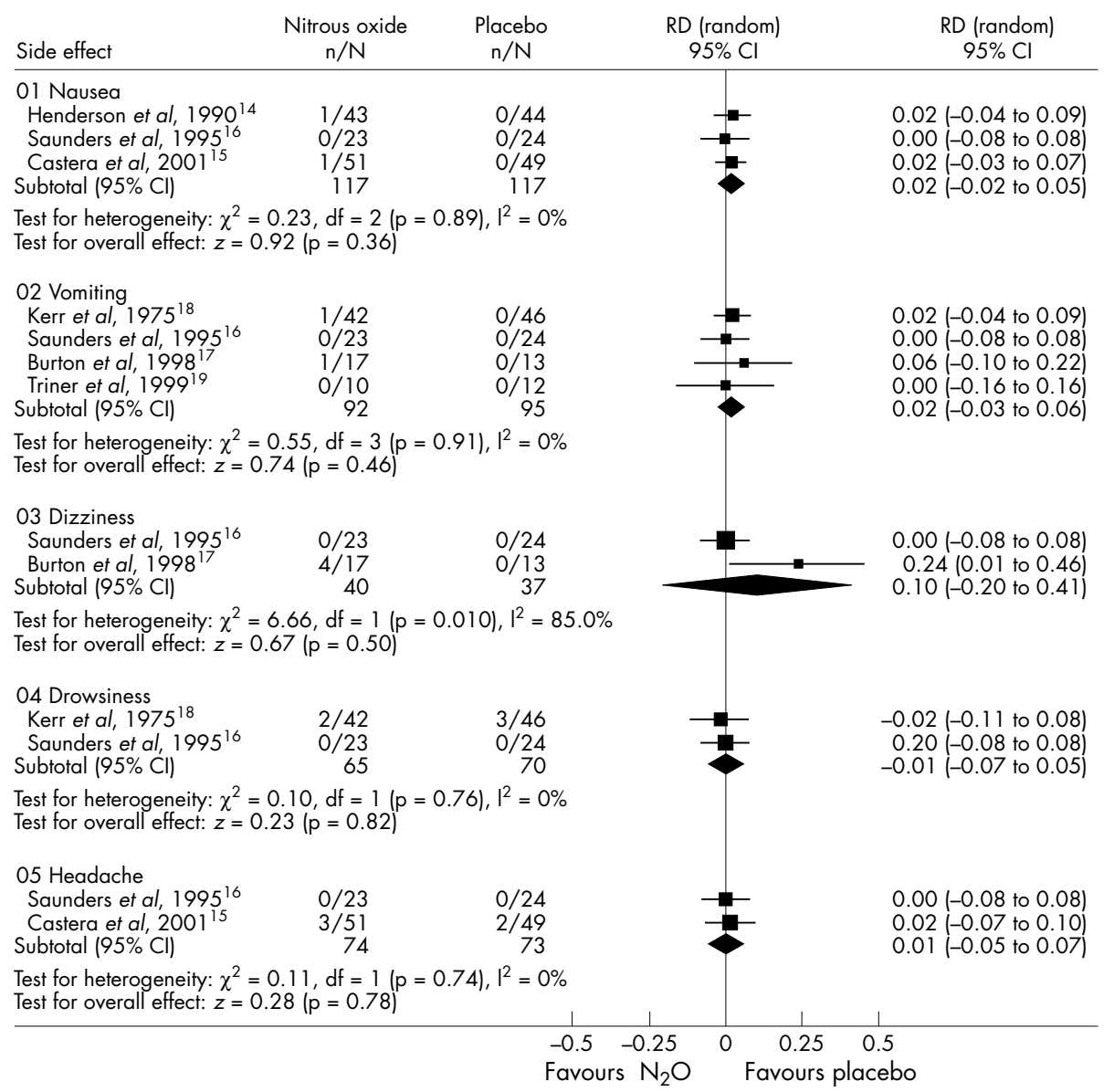

Figure 1 Pooled analysis of adverse effects from studies comparing $50 \%$ nitrous oxide $\left(\mathrm{N}_{2} \mathrm{O}\right)$ with placebo.

\section{Drowsiness}

Two studies assessed drowsiness in 135 patients treated with $50 \%$ nitrous oxide or placebo. ${ }^{16}{ }^{18}$ The pooled result of these studies showed that $3 \%$ of patients treated with nitrous oxide analgesia and $4 \%$ of patients treated with placebo experienced drowsiness, indicating that drowsiness was probably unrelated to nitrous oxide inhalation (RD - 1\%, 95\% CI - 7\% to $5 \%, \mathrm{p}=0.8$ ).

\section{Headache}

Saunders et $^{1 l^{16}}$ found no occurrences of headache in a group of 47 patients treated with $50 \%$ nitrous oxide or placebo. Although Castera et al $^{15}$ demonstrated a higher incidence of headache in patients treated with $50 \%$ nitrous oxide or placebo, there was no difference in the incidence of headache between their two groups (fig 1). Similarly, NotiniGudmarsson et $a l^{10}$ did not receive any reports of headache in 38 patients treated with $50 \%$ nitrous oxide or intramuscular pethidine.

\section{Hypotension}

Saunders et al $^{20}$ reported hypotensive episodes in only 2 of 30 patients $(7 \%)$ treated with $50 \%$ nitrous oxide compared with 4 of 30 patients (13\%) given placebo during colonoscopy. Hence, episodes of hypotension appeared to be due to the colonoscopy rather than the nitrous oxide therapy (RD $-7 \%$, $95 \%$ CI $-22 \%$ to $8 \%$ ). Furthermore, the incidence of hypotension in patients who were treated with nitrous oxide was lower than in patients treated with intravenous midazolam and pethidine (14\%).

\section{Oxygen desaturation}

Only one study compared episodes of oxygen desaturation in patients treated with $50 \%$ nitrous oxide or placebo. ${ }^{17}$ There were no significant oxygen desaturation events in any of the patients. Two studies compared episodes of oxygen desaturation in patients treated with either $50 \%$ nitrous oxide or conventional analgesia. ${ }^{10}{ }^{20}$ There were no episodes of oxygen desaturation in 49 patients who were treated with nitrous oxide compared with nine episodes in 48 patients treated with pethidine, with or without midazolam (RD - 10\%, 95\% CI $-1 \%$ to $-78 \%, p=0.03$ ).

\section{Recovery time}

Table 3 summarises the results from studies measuring recovery times in patients treated with $50 \%$ nitrous oxide or either placebo or conventional analgesic medication. All of the studies comparing 50\% nitrous oxide with conventional analgesia showed a significantly shorter recovery time for patients treated with nitrous oxide. ${ }^{10}{ }^{20-22}$ One of these studies also compared recovery time in patients treated with $50 \%$ nitrous oxide and those treated with placebo. ${ }^{20}$ There was no significant difference in recovery times after the two treatments.

\section{Additional medication}

Table 4 compares the number of patients treated with $50 \%$ nitrous oxide requiring additional medication with those given either placebo or conventional analgesia. Two studies compared the need for additional medication in patients receiving either nitrous oxide or placebo. Significantly fewer patients treated with nitrous oxide required additional 
Table 3 Comparison of recovery time of patients receiving $50 \%$ nitrous oxide $\left(\mathrm{N}_{2} \mathrm{O}\right)$ and patients given placebo or conventional analgesia

\begin{tabular}{|c|c|c|c|c|c|c|}
\hline \multirow[b]{2}{*}{ Study } & \multirow{2}{*}{$\begin{array}{l}\text { No of } \\
\text { patients }\end{array}$} & \multirow{2}{*}{$\begin{array}{l}\text { Study } \\
\text { population }\end{array}$} & \multirow[b]{2}{*}{ Pain source } & \multicolumn{2}{|c|}{ Recovery time (min) } & \multirow[b]{2}{*}{$p$ value } \\
\hline & & & & $50 \% \mathrm{~N}_{2} \mathrm{O}$ & Control & \\
\hline \multicolumn{7}{|l|}{$50 \%$ nitrous oxide $v$ placebo } \\
\hline \multicolumn{7}{|c|}{$50 \%$ nitrous oxide $v$ conventional medication } \\
\hline Forbes and Collins, $2000^{22}$ & 102 & Adult & Colonoscopy & $30(30-45)$ & $60(30-110)$ & $<0.0001$ \\
\hline Notini-Gudmarsson et al, $1996^{10}$ & 38 & Adult & Colonoscopy & $49(28-148)$ & $83(29-300)$ & $<0.05$ \\
\hline Evans et al, $1995^{1}$ & 30 & Children & Fracture reduction & $30(15-60) \dagger$ & $83(60-150) \dagger$ & $<0.01$ \\
\hline Saunders et al, $1994^{20}$ & 59 & Adult & Colonoscopy & $32^{*}$ & $60^{*}$ & $<0.001$ \\
\hline Lindblom et al, $1994^{21}$ & 50 & Adult & Colonoscopy & $0(0-5) \ddagger$ & $37.5(10-75) \pm$ & 0.0001 \\
\hline
\end{tabular}

medication compared with those who received placebo. ${ }^{19} 20$ Four studies compared the need for additional medication in patients receiving either nitrous oxide or conventional medication. There was no significant difference between the groups in the need for additional medication in three of the studies. ${ }^{10}{ }^{20-21}$ In contrast, Harrison et $a l^{23}$ found that patients treated with pethidine and promazine during labour needed additional medication more often than patients who were treated with nitrous oxide. In this study, pethidine and promazine were administered intramuscularly in doses similar to in other studies in which similar drugs were administered intravenously.

\section{DISCUSSION}

This systematic review demonstrates that $50 \%$ nitrous oxide, when used by trained personnel in a medical setting, is a safe form of analgesia. When viewed in conjunction with previous studies on efficacy, $50 \%$ nitrous oxide provides effective analgesia for a range of injuries with minimal side effects. Serious adverse effects such as hypotension and oxygen desaturation have not been shown to occur during treatment with nitrous oxide. In addition, patients treated with 50\% nitrous oxide recover faster and do not require additional medication any more frequently than patients treated with intravenous analgesia.

For a number of years, many organisations throughout the world, including some employing caregivers not trained as emergency medical technicians, have made use of $50 \%$ nitrous oxide analgesia. Until now there has not been a summary evidence base for the safety of this form of analgesia. The results of this review suggest that $50 \%$ nitrous oxide may be safe even when used by caregivers who do not possess medical, nursing, or EMT qualifications. This review reinforces the ongoing use of $50 \%$ nitrous oxide by these groups.

Primary care organisations currently allowing lay responders to use $50 \%$ nitrous oxide have strict criteria for certification. In most cases, caregivers must possess advanced first aid and advanced resuscitation certification, and often require a mandatory period of experience before training to use analgesic gases. This ensures the carer has adequate underlying knowledge to rule out contraindications and deal with any complications that may arise. In addition, there are strict controls on security to avoid illicit abuse, as well as guidelines to ensure adequate venting of exhaled gas and environmental safety. The method of self-administration is itself a safety feature of $50 \%$ nitrous oxide. If a patient loses consciousness, the mask falls away from the face allowing inhalation of ambient air. The patient then rapidly regains consciousness.

As with any intervention in any area of patient care, some injuries and conditions preclude the safe use of nitrous oxide in the prehospital setting. Nitrous oxide diffuses rapidly into gas filled cavities, actually diffusing in faster than nitrogen can diffuse out. ${ }^{19}$ As a consequence, air filled cavities will increase in volume, pressure, or both. Nitrous oxide is therefore contraindicated in patients who are suspected of having a pneumothorax, bowel obstruction, or decompression sickness. Fifty percent nitrous oxide has a disproportionately stronger effect in patients who are intoxicated, or under the influence of sedatives or opioids, ${ }^{24}$ or who have a depressed level of consciousness. Nitrous oxide may induce unconsciousness in these patients. It should not be given to patients with head injury as it is known to increase intracranial pressure. ${ }^{25}$ It has also been suggested that a patient who is hypovolaemic may lose consciousness more readily while inhaling 50\% nitrous oxide. ${ }^{26}$ Nitrous oxide/oxygen mixtures separate when stored below $5^{\circ} \mathrm{C}$ and must be rewarmed and remixed before use. There are, therefore, a number of important contraindications to nitrous oxide therapy.

Although this review advocates the use of nitrous oxide by members of the community who are not trained as EMTs, it is important that a major focus of training this group is the

Table 4 Need for additional medication in patients receiving $50 \%$ nitrous oxide $\left(\mathrm{N}_{2} \mathrm{O}\right)$ compared with placebo or conventional analgesia

\begin{tabular}{|c|c|c|c|c|c|c|}
\hline \multirow[b]{2}{*}{ Study } & \multirow{2}{*}{$\begin{array}{l}\text { No of } \\
\text { patients }\end{array}$} & \multirow{2}{*}{$\begin{array}{l}\text { Study } \\
\text { population }\end{array}$} & \multirow[b]{2}{*}{ Pain source } & \multicolumn{2}{|c|}{$\begin{array}{l}\text { Additional medication } \\
\text { (n }(\%))\end{array}$} & \multirow[b]{2}{*}{$p$ value } \\
\hline & & & & $50 \% \mathrm{~N}_{2} \mathrm{O}$ & Control & \\
\hline \multicolumn{7}{|l|}{$50 \%$ nitrous oxide $v$ placebo } \\
\hline Triner et al, $1999^{19}$ & 22 & Adult & Migraine headache & $2(20)$ & $10(83)$ & 0.008 \\
\hline Saunders et al, $1994^{20}$ & 60 & Adult & Colonoscopy & $3(10)$ & $13(43)$ & 0.007 \\
\hline \multicolumn{7}{|c|}{$50 \%$ nitrous oxide $v$ conventional medication } \\
\hline Notini-Gudmarsson et al, $1996^{10}$ & 38 & Adult & Colonoscopy & $0(0)$ & $1(5)$ & 0.31 \\
\hline Saunders et al, $1994^{20}$ & 59 & Adult & Colonoscopy & $3(10)$ & 5 (17) & 0.47 \\
\hline Lindblom et al, $1994^{21}$ & 50 & Adult & Colonoscopy & $1(4)$ & $5(20)$ & 0.19 \\
\hline Harrison et al, $1987^{23}$ & 70 & Adult & Labour & $1(5)$ & $40(80)$ & $<0.0001$ \\
\hline
\end{tabular}


ability to suspect or identify conditions in which the use of nitrous oxide may be dangerous. In a recent study of continuous positive airway pressure for cardiogenic pulmonary oedema, EMTs failed to identify the presence of contraindications in four of 17 patients. ${ }^{27}$ The authors of that study stressed the need to focus attention during training on identifying important contraindications when introducing new techniques. ${ }^{27}$

All of these factors should be encompassed in a clear protocol, supervised and regularly revised by a medical director, before members of a first aid or primary care organisation are accredited to provide analgesia with 50\% nitrous oxide. The National Association of Emergency Medical Service Physicians (NAEMSP) position statement on the use of nitrous oxide in prehospital emergency care states that nitrous oxide is within the scope of practice of EMS medical directors and can be used by EMS field personnel following appropriate education and training. ${ }^{28}$ Our review suggests that with appropriate training, nonEMS care providers can also safely use the analgesic benefits of $50 \%$ nitrous oxide.

Randomised studies included in this review included a variety of patient populations and a broad spectrum of pain sources. Application of the findings of this review to prehospital care is appropriate because of the consistency of the results across such a heterogeneous group of studies.

Although our aim was to demonstrate the safety of 50\% nitrous oxide in prehospital care, there are no randomised controlled studies investigating adverse effects from 50\% nitrous oxide in this setting. Numerous case series exist, but this study design excludes investigation of cause and effect (that is, which adverse effects are due to nitrous oxide inhalation and which effects would have occurred anyway). Our analysis was confined to randomised controlled studies comparing 50\% nitrous oxide analgesia with either placebo or conventional medication. As a result, comparisons between nitrous oxide and conventional medication regimens are based on a small number of studies for most of the adverse outcomes considered. Even when pooled analysis of multiple studies was possible, the evidence for equivalence is good, but not always definitive.

A potential weakness of this review is the methodological quality of the primary studies. As shown in table 2, only seven of the 12 randomised studies included in this review gave adequate information on the method of randomisation. Five of these studies gave information on allocation concealment. Eight studies gave adequate information on the methods of blinding. However, collection of outcome data was complete in nearly all studies.

\section{CONCLUSIONS}

Fifty per cent nitrous oxide has previously been shown to have similar efficacy for pain relief for a range of procedures compared to conventional analgesia with intravenous analgesic regimens, including opioid analgesia. This review has shown that side effects are uncommon and major adverse events such as hypotension and oxygen desaturation could not be attributed to nitrous oxide inhalation. Recovery from sedative effects of nitrous oxide is faster compared with intravenous analgesia.

Nitrous oxide at a concentration of $50 \%$ is an effective and safe form of analgesia. The side effect profile of this agent suggests that it could be used safely by adequately trained lay persons in the prehospital setting.

\footnotetext{
Authors' affiliations

S C Faddy, Department of Cardiology, St Vincent's Hospital, Sydney, Australia
}

S R Garlick, Department of Anaesthetics, St Vincent's Hospital, Sydney, Australia

Competing interests: none declared

This work has been presented in part at the 2nd International Life Saving Medical-Rescue Conference, Broadbeach, Australia, August 2001.

\section{REFERENCES}

1 Evans JK, Buckley SL, Alexander $\mathrm{AH}$, et al. Analgesia for the reduction of fractures in children: A comparison of nitrous oxide with intramuscular sedation. J Pediatr Orthop 1995;15:73-7.

2 Latto IP, Molloy MJ, Rosen M. Arterial concentrations of nitrous oxide during intermittent patient-controlled inhalation of $50 \%$ nitrous oxide in oxygen (Entonox) during the first stage of labour. Br J Anaesth 1973:45:1029-34.

3 Einarsson S, Stenqvist $O$, Bengtsson A, et al. Gas kinetics during nitrous oxide analgesia for labour. Anaesthesia 1996;51:449-52.

4 Baskett PJF, Eltringham RJ, Bennett JA. An assessment of the oxygen tensions obtained with pre-mixed $50 \%$ nitrous oxide and oxygen mixture (Entonox) used for pain relief. Anaesthesia 1973;28:449-50.

5 Wilkins CJ, Reed PN, Aitkenhead AR. Hypoxaemia after inhalation of $50 \%$ nitrous oxide and oxygen. Br J Anaesth 1989;63:346-7.

6 Arfeen Z, Armstrong PJ, Whiffield A. The effects of Entonox and epidural analgesia on arterial oxygen saturation of women in labour. Anaesthesia 1994:49:32-4.

7 Carstinou J, Levytam S, Norman P, et al. Nitrous oxide in early labour: Safety and analgesic efficacy assessed by a double-blind, placebo-controlled study. Anesthesiology 1994;80:30-5.

8 Zelcher J, Owers H, Paull JD. A controlled oximetric evaluation of inhalational, opioid and epidural analgesia in labour. Anaesth Intensive Care 1989;17:418-21

9 Bezzant JL. Nitrous oxide diffusion. University of Utah. Available at: wysiwyg: //210/ http://www-medlib.med.utah.edu/kw/derm/pages/ni05_1.htm (accessed 4 August 2001).

10 Notini-Gudmarsson AK, Dolk A, Jakobsson J, et al. Nitrous oxide: A valuable alternative for pain relief and sedation during routine colonoscopy. Endoscopy 1996;28:283-7.

11 Faddy SC, Garlick SR. Prehospital pain relief with 50\% nitrous oxide: an option for all first responders. 2nd International Lifesaving Federation Medical Rescue Conference. 20-22 August 2001, Broadbeach, Queensland.

12 Zacny JP, Cho AL, Coalson DW, et al. Differential acute tolerance development to effects of nitrous oxide in humans. Neurosci Lett 1996:209:73-6.

13 Fagan D, Paul DL, Tiplady B, et al. A dose-response study of the effects of inhaled nitrous oxide on psychological performance and mood. Psychopharmacology 1994;116:333-8.

14 Henderson JM, Spence DG, Komocar LM, et al. Administration of nitrous oxide to pediatric patients provides analgesia for venous cannulation. Anesthesiology 1990;72:269-71

15 Castera L, Negre I, Samii K, et al. Patient-administered nitrous oxide/oxygen provides safe and effective analgesia for percutaneous liver biopsy: A randomized placebo-controlled trial. Am J Gastroentol 2001;96:1553-7.

16 Saunders BP, Elsby B, Boswell AM, et al. Intravenous antispasmodic and patient-controlled analgesia are of benefit for screening flexible sigmoidoscopy. Gastrointest Endosc 1995;42:123-7.

17 Burton JH, Auble TE, Fuchs SM. Effectiveness of 50\% nitrous oxide/50\% oxygen during laceration repair in children. Acad Emerg Med 1998:5:112-17.

18 Kerr F, Hoskins MR, Brown MG, et al. A double-blind trial of patientcontrolled nitrous-oxide/oxygen analgesia in myocardial infarction. Lancet 1975; 1:1397-400

19 Triner WR, Bartfield JM, Birdwell M, et al. Nitrous oxide for the treatment of acute migraine headache. Am J Emerg Med 1999;17:252-4.

20 Saunders BP, Fukumoto $M$, Halligan S, et al. Patient-administered nitrous oxide/oxygen inhalation provides effective sedation and analgesia for colonoscopy. Gastrointest Endosc 1994;40:418-21.

21 Lindblom A, Jansson O, Jeppsson B, et al. Nitrous oxide for colonoscopy discomfort: a randomised double-blind study. Endoscopy 1994;26:283-6.

22 Forbes GM, Collins BJ. Nitrous oxide for colonoscopy: a randomised controlled study. Gastrointest Endosc 2000;51:271-7.

23 Harrison RF, Shore M, Woods T, et al. A comparative study of transcutaneous electrical nerve stimulation (TENS), Entonox, pethidine + promazine and lumbar epidural for pain relief in labor. Acta Obstet Gynecol Scand 1987;66:9-14

24 Morgan GE, Mikhail MS. Clinical Anesthesiology. Connecticut: Appleton \& Lange, 1992:106.

25 Moss E, McDowall DG. ICP increases with $50 \%$ nitrous oxide in oxygen in severe head injuries during controlled ventilation. $\mathrm{Br} J$ Anaesth 1979;51:757-60

26 Gibson H, Palmer A. Inhalation analgesia with premixed nitrous oxideoxygen Entonox. University of Queensland, 1995. Available at: http:// gasbone.herston.uq.edu.au/teach/su602/docs/e27_0ent.html (accessed 4 August 2001).

27 Kosowsky JM, Stephanides SL, Branson RD, et al. Prehospital use of continuous positive airway pressure (CPAP) for presumed pulmonary oedema: A preliminary case series. Prehosp Emerg Care 2001;5:190-6.

28 Stewart RD, Tortella BJ. Use of nitrous oxide:oxygen mixtures in prehospital emergency care. National Association of EMS Physicians. 1990. Available at: http://www.naemsp.org/Position\%20Papers/Nitrous\%200xide.html (accessed 28 August 2002). 